\title{
Effect of thidiazuron and gibberellic acid on leaf yellowing of cut stock flowers
}

Research Article

Antonio Ferrante ${ }^{1 *}$, Anna Mensuali-Sodi², Giovanni Serra²

${ }^{1}$ Departament of Plant Production, Università degli Studi di Milano, 20133 Milano, Italy

${ }^{2}$ Sant'Anna School of Advanced Studies, 56100 Pisa, Italy

Received 12 March 2009; Accepted 14 April 2009

Abstract: Plant hormones such as cytokinins and gibberellins are able to inhibit leaf yellowing in different species of cut flowers and potted plants. These hormones can be used alone or in combination among them for preserving chlorophyll in floriculture items. In the present study thidiazuron was tested alone or combined with $\mathrm{GA}_{3}$ for delaying leaf yellowing of cut stock flowers during vase life. Cut flowers were placed in a controlled environment and treated for 24 hours with the following solutions: distilled water (control) or solutions containing $5,10 \mu \mathrm{M}$ thidiazuron (TDZ), $0.5 \mathrm{mM}$ gibberellic acid $\left(\mathrm{GA}_{3}\right)$, or a combination of $0.5 \mathrm{mM} \mathrm{GA}_{3}$ with $5 \mu \mathrm{M}$ TDZ. The effect of treatments was evaluated by measuring chlorophyll content, ethylene production, leaf gas exchanges and chlorophyll a fluorescence. Results showed that TDZ was able to delay leaf yellowing in light during whole experimental period (30 days). The effect of TDZ on dark stored flowers was less effective, and also delayed chlorophyll losses for 10-12 days. TDZ and GA ${ }_{3}$ combination did not show any synergistic nor beneficial effect. Gas exchange values such as net photosynthesis, vapour pressure deficit, stomatal conductance and water use efficiency were higher in the TDZ only treatment.

Keywords: Chlorophyll • Ethylene • Gibberellin • Postharvest Senescence • Thidiazuron

(c) Versita Warsaw and Springer-Verlag Berlin Heidelberg.

\section{Introduction}

Leaf yellowing is a form of leaf senescence that is both highly programmed and genetically regulated [1]. This leaf yellowing is not only age dependent, but it can be induced by many factors including pathogens, mechanical damage, harvesting or abiotic stresses. Cut flowers may be more or less sensitive to leaf yellowing depending from the species and cultivars [2]. Cut flowers that show leaf yellowing before petal wilting lose their commercial value and have shorter marketable period. The postharvest factors that enhance the leaf yellowing can be inadequate storage conditions, lack of endogenous cytokinins, presence of ethylene, darkness, accumulation of abscisic acid (ABA), leaf age or mechanical injury. Several commercial formulations are available for preventing leaf yellowing of cut flowers and are usually a combination of cytokinins and gibberellins [3]. The cytokinin usually used is 6-benzyladenine, while the commercial compounds containing gibberellins are a mix of $\mathrm{GA}_{3}, \mathrm{GA}_{4}$ and $\mathrm{GA}_{4+7}$. In some cut flowers the lack of cytokinins induced by the harvest may be the main cause of leaf yellowing. In fact, exogenous applications of cytokinins can greatly delay leaf discoloration [4-6]. Analogously, exogenous applications of $\mathrm{GA}_{3}$ with concentrations that ranged between $10^{-4}$ and $10^{-5} \mathrm{M}$ were able to prevent leaf yellowing in cut alstroemeria flowers $[4,7]$. In this species it has been found that leaf yellowing can be also delayed either by a continuous treatment with $1 \mu \mathrm{M}$ thidiazuron (TDZ, N-phenyl-N'1,2,3-thiadiazol-5-ylurea) or by a pulse treatment for $24 \mathrm{~h}$ with $10 \mu \mathrm{M}$ TDZ [2]. TDZ is a substituted phenylurea 
registered as a plant growth regulator that is commonly used in tissue culture for its powerful cytokinin-like activity. It is about $50-100$ times more active than common cytokinins as observed in in vitro experiments [8]. The aim of this work was to investigate the effect of TDZ alone or in combination with gibberellins, such as $\mathrm{GA}_{3}$, on leaf yellowing and flower senescence of cut stock flowers. The synergism between TDZ and $\mathrm{GA}_{3}$ may be useful for preventing leaf yellowing of cut flowers dark stored or transported for a short or long period of time.

\section{Experimental Procedures}

\subsection{Plant material and environmental conditions}

Cut stock (Matthiola incana L.) flowers were bought directly from a cooperative of flower growers (Florexport, Viareggio Italy). Cut flowers were selected to avoid malformations or damage related with harvesting and transport handling. Flower stems were cut to $60 \mathrm{~cm}$ and placed in distilled water in a postharvest room equipped with a controlled environment maintained at $20^{\circ} \mathrm{C}, 60 \%$ relative humidity and $15 \mu \mathrm{mol} \mathrm{m} \mathrm{m}^{-2} \mathrm{~s}^{-1}$ light intensity for $12 \mathrm{~h}$ day $^{-1}$ by cool-white fluorescent lamps.

\subsection{Light versus dark storage with or without TDZ}

Cut stock flowers were placed in distilled water (control) or vase solution containing $10 \mu \mathrm{M}$ thidiazuron (TDZ) in dark or light condition ( $15 \mu \mathrm{mol} \mathrm{m} \mathrm{m}^{-2} \mathrm{~s}^{-1}$ for $12 \mathrm{~h}$ day ${ }^{-1}$ ) in the postharvest room until the end of experiments (continuous treatments). Each experiment was considered complete when leaf or flowers showed senescence symptoms.

\subsection{Chemical treatments}

Cut flowers were pulse treated for $24 \mathrm{~h}$ in dark or light condition $\left(15 \mu \mathrm{mol} \mathrm{m} \mathrm{m}^{-2} \mathrm{~s}^{-1}\right.$ for $\left.12 \mathrm{~h} \mathrm{day}^{-1}\right)$. After the pulse treatment the vase solutions were replaced with distilled water. All treated flowers were maintained in the postharvest room in the same light intensity and photoperiod applied during the pulse treatments. Cut flowers were placed in water (control) or vase solution containing 5, $10 \mu \mathrm{M}$ TDZ (Duchefa), $0.5 \mathrm{mM}$ gibberellic acid $\left(\mathrm{GA}_{3}\right.$, Sigma) or combination of $0.5 \mathrm{mM} \mathrm{GA}_{3}$ plus $5 \mu \mathrm{M}$ TDZ.

\subsection{Chlorophyll determination and ethylene measurement}

Total chlorophyll was determined from $10 \mathrm{~mm}$ diameter discs (3 discs for each plant sample). Leaf pigments were extracted using $99 \%$ methanol and samples were kept in darkness at $4^{\circ} \mathrm{C}$ for $24 \mathrm{~h}$. The absorbance readings were taken at $665.2 \mathrm{~nm}$ and $652.4 \mathrm{~nm}$. Total chlorophyll content was calculated as described by Lichtenthaler [9]. Total chlorophyll was measured in light and dark conditions with or without $10 \mu \mathrm{M}$ TDZ treatments and in the $\mathrm{GA}_{3}$ experiments under light conditions.

Ethylene production was measured by enclosing either flowers detached from the spikes or leaf disks in airtight containers $(30 \mathrm{ml})$. Two $\mathrm{ml}$ gas samples were taken from the headspace of the containers with a hypodermic syringe after $1 \mathrm{~h}$ incubation at room temperature. The ethylene concentration in the sample was measured by gas chromatograph (HP5890, Hewlett-Packard, Menlo Park, CA) using a flame ionisation detector (FID), a stainless steel column $(150 \times 0,4 \mathrm{~cm} \varnothing$ packed with Hysep T), column and detector temperatures of $70^{\circ}$ and $350^{\circ} \mathrm{C}$, respectively, and nitrogen carrier gas at a flow rate of $30 \mathrm{ml} \mathrm{min}^{-1}$. Quantification was performed against an external standard and results were expressed on a fresh weight basis ( $\mathrm{pl} \mathrm{h}^{-1} \mathrm{~g}^{-1} \mathrm{~F}$.W.). Ethylene production was measured in the $\mathrm{GA}_{3}$ experiments under light conditions.

\subsection{Leaf gas exchange}

Leaf gas exchange was measured using a temperaturecontrolled assimilation chamber, connected with Infrared Gas Analyser (IRGA) in an open gas exchange system (Heinz Walz, Effeltrich, Germany). $\mathrm{CO}_{2}$-exchange was measured at constant flow of $1200 \mathrm{ml} \mathrm{min}^{-1}$ under $400 \mu \mathrm{mol} \mathrm{m} \mathrm{m}^{-2} \mathrm{~s}^{-1}$ light intensity. Net photosynthetic rate, air to leaf vapor pressure deficit (ALVPD), total conductance for water vapour concentration was calculated according to the equations reported by Von Caemmerer and Farquhar [10]. The instantaneous water use efficiency (WUE) was calculated as ratio between net photosynthesis $(P)$ and stomatal conductance $\left(\mathrm{gH}_{2} \mathrm{O}\right)$ [11]. Gas exchange analyses were measured in the $\mathrm{GA}_{3}$ experiments under light conditions.

\subsection{Chlorophyll a fluorescence}

The fluorescence of chlorophyll a was determined on dark adapted leaves, randomly taken from the stems and incubated for $40 \mathrm{~min}$ at room temperature. Chlorophyll a fluorescence (expressed in relative units) was measured using a portable Handy Plant Efficiency Analyser (PEA, Hansatech, UK). Leaf fluorescence was determined after illumination with a light intensity of $3000 \mu \mathrm{mol} \mathrm{m} \mathrm{m}^{-2} \mathrm{~s}^{-1}$. The fluorescence parameters were calculated automatically: fluorescence level when plastoquinone electron acceptor pool ( $\mathrm{Qa}$ ) is fully oxidised (Fo), variable fluorescence ( $F v=F m-F o)$, maximum fluorescence $(F m)$, maximum quantum efficiency of photosystem II (Fv/Fm). 
Chlorophyll a fluorescence was measured in the $\mathrm{GA}_{3}$ experiments under light conditions.

\subsection{Leaf yellowing, flower senescence and vase life}

The effects of chemical treatments were evaluated by daily observations of leaf yellowing and petal wilting appearance. The useful vase life was considered as the minor value between the leaf yellowing and flower senescence.

\subsection{Statistical analysis}

The data are reported in figures and table as means with standard errors. Each treatment was composed of six replicate stems. The data were subjected to oneway analysis of variance and the differences among treatments were analysed by Bonferroni's multiple comparison test. Experiments were repeated two times.

\section{Results}

\subsection{Light versus dark storage with or without TDZ}

Preliminary experiments were performed for evaluating the effectiveness of TDZ on preventing leaf yellowing in cut stock flowers. Treated flowers were placed in either light or dark conditions. The chlorophyll losses were visible from leaves of cut stems after 3 or 6 days from the beginning of the experiment, when flowers were stored in dark or light respectively. The chlorophyll content in cut stock leaves decreased in all treatments except in those stored in light conditions treated with TDZ (Figure 1A). The chlorophyll content in leaves of control flowers, placed in light, was halved after 10 days, while in dark the chlorophyll degradation was stronger. In dark treatments, the chlorophyll content of leaves was reduced by $75 \%$ when compared with the initial value. Cut flowers treated with TDZ did not show any chlorophyll decline in light, while in dark the leaf chlorophyll slowly decreased.

\subsection{Effects of chemical treatments}

\subsubsection{Vase life}

The vase life of cut stock flowers was efficiently delayed by pulse treatments with 5 or $10 \mu \mathrm{M}$ TDZ, which inhibited leaf yellowing during the whole experimental period (30 days). Unfortunately, TDZ did not have the same effect on petal wilting (Table 1). Pulse treatments with solutions containing $\mathrm{GA}_{3}$ slightly delayed the leaf

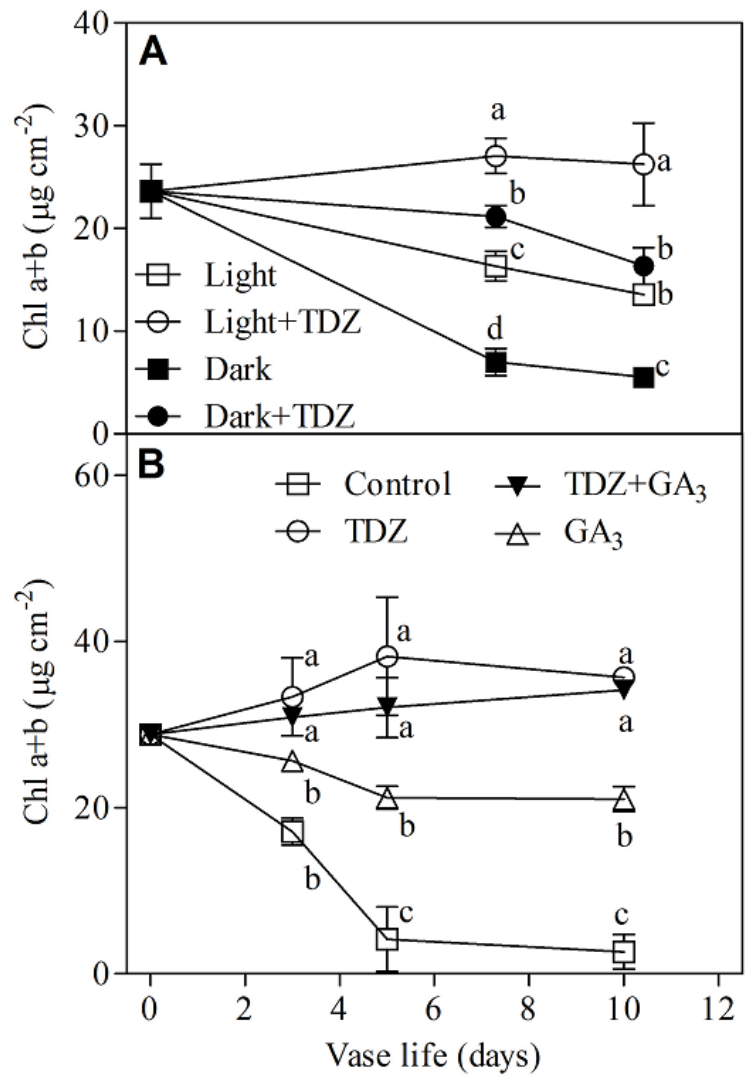

Figure 1. A) Total chlorophyll concentration $\left(\mu \mathrm{g} \mathrm{cm}^{-2}\right)$ of cut stock leaves harvested from cut flowers placed in distilled water in dark (Dark) or in light/dark condition (Light) and in solution containing $10 \mu \mathrm{M}$ TDZ in dark (Dark+TDZ) or in light condition (Light+TDZ) . B) Total chlorophyll in stock leaves from cut stems $24 \mathrm{~h}$ pulse treated with distilled water (Control), $5 \mu \mathrm{M}$ TDZ, $5 \mu \mathrm{M}$ TDZ plus $0.5 \mathrm{mM} \mathrm{GA}_{3}$ or $0.5 \mathrm{mM} \mathrm{GA}_{3}$ under light conditions. Values are the means with the relative standard errors of six leaves randomly harvested during the vase life. Data were subjected to one-way analysis of variance and differences among treatments were analysed by Bonferroni post-test. Different letters denote significant differences at $P \leq 0.05$.

yellowing of cut stock flowers compared to controls and slightly increased the vase life, but did not prevent flower senescence. In fact, the flowers treated with $\mathrm{GA}_{3}$ showed almost simultaneously leaf yellowing and flower senescence. The $\mathrm{GA}_{3}$ treatment was also tested during dark storage, but this did not inhibit leaf yellowing (Table 1). Pulse treatments with TDZ plus $\mathrm{GA}_{3}$ delayed leaf yellowing during all the experimental period (30 days) in light conditions, but this was not the case for dark conditions. The presence of $\mathrm{GA}_{3}$ in the preserving solution did not show any intereaction with TDZ ( $P>0.05)$. In fact, $G_{3}$ did not give any additional benefit in preserving leaf colour in both light and dark conditions (Table 1). 


\begin{tabular}{|c|c|c|c|c|}
\hline \multirow{3}{*}{ Treatments } & \multicolumn{2}{|c|}{ Leaf yellowing } & \multirow{3}{*}{$\begin{array}{l}\text { Petal wilting } \\
\text { (days) }\end{array}$} & \multirow{3}{*}{$\begin{array}{l}\text { Vase life } \\
\text { (days) }\end{array}$} \\
\hline & (days) & (days) & & \\
\hline & Light & Dark & & \\
\hline Control & $7.2 \pm 0.62 \mathrm{c}$ & $3.7 \pm 0.22 b$ & $7.9 \pm 0.74 b$ & $7.2 \pm 0.62 b$ \\
\hline $5 \mu \mathrm{M}$ TDZ & $30.0 \pm 0.00 a$ & $14.9 \pm 0.42 \mathrm{a}$ & $10.0 \pm 0.84 a b$ & $10.0 \pm 0.84 a$ \\
\hline $10 \mu \mathrm{M}$ TDZ & $30.0 \pm 0.00 a$ & $14.4 \pm 0.85 a$ & $11.2 \pm 0.75 \mathrm{a}$ & $11.2 \pm 0.75 \mathrm{a}$ \\
\hline $5 \mu \mathrm{M} \mathrm{TDZ}+0.5 \mathrm{mM} \mathrm{GA}_{3}$ & $30.0 \pm 0.00 \mathrm{a}$ & $14.5 \pm 1.28 \mathrm{a}$ & $9.5 \pm 0.43 b$ & $9.5 \pm 0.43 \mathrm{a}$ \\
\hline $0.5 \mathrm{mM} \mathrm{GA}_{3}$ & $9.8 \pm 0.31 b$ & $3.9 \pm 0.21 b$ & $9.8 \pm 0.70 b$ & $9.8 \pm 0.31 \mathrm{a}$ \\
\hline
\end{tabular}

Table 1. Leaf yellowing (light or dark conditions), flower senescence (light) and vase life (minus value between leaf and flower senescence) in cut stock flowers pulse treated for $24 \mathrm{~h}$ with distilled water (Control), 10 or $5 \mu \mathrm{M}$ TDZ, $5 \mu \mathrm{M}$ TDZ plus $0.5 \mathrm{mM} \mathrm{GA}$ or $0.5 \mathrm{mM} \mathrm{GA}_{3}$. Values are means with standard errors. Data were subjected to one-way analysis of variance and differences among treatments were analysed by Bonferroni post-test. Different letters denote significant differences at $\mathrm{P} \leq 0.05$.

\subsubsection{Chlorophyll degradation}

Pulse treatments with $5 \mu \mathrm{M}$ TDZ did not show chlorophyll reduction when placed in light conditions for vase life evaluation (Figure 1B). The $\mathrm{GA}_{3}$ treatment alone delayed leaf yellowing in light conditions in respect to the control, but its effect was not comparable with results obtained between TDZ and the control. Leaf yellowing of darkstored fl owers was not signifi cantly delayed by $\mathrm{GA}_{3}$ treatment (Table 1). The combinations of $\mathrm{GA}_{3}$ with $\mathrm{TDZ}$ prevented chlorophyll degradation and no statistical differences were found between TDZ plus $\mathrm{GA}_{3}$ and TDZ treatments (Figure 1B).

\subsubsection{Ethylene production}

Ethylene production was measured from leaves and flowers detached randomly from the cut stems of each treatment, at different timing during vase life. Ethylene production was statistically different after one and five days in flowers of cut stems treated with TDZ combined with $\mathrm{GA}_{3}$ (Figure 2A). In leaf tissues the effect of TDZ plus $\mathrm{GA}_{3}$ was only found after 5 days of vase life (Figure 2B). Among treatments the combination of TDZ with $\mathrm{GA}_{3}$ induced the highest values of ethylene production; about 10 fold higher in leaves and 4 fold higher in flowers than the control treatment.

\subsubsection{Leaf gas exchanges}

The leaf functionality was estimated by leaf gas exchange measurements. Values of net photosynthesis (NP) at beginning of experiments were $7 \mu \mathrm{mol} \mathrm{m}^{-2} \mathrm{~s}^{-1}$ and declined in all treatments during vase life (Figure $3 \mathrm{~A}$ ). The higher values were observed in leaves of cut flowers treated with TDZ, and TDZ plus GA . After 10 days the values of NP in TDZ and TDZ plus $\mathrm{GA}_{3}$ treatments were $4 \mu \mathrm{mol} \mathrm{m} \mathrm{m}^{-2} \mathrm{~s}^{-1}$ while control leaves were $2 \mu \mathrm{mol}$ $\mathrm{m}^{-2} \mathrm{~s}^{-1}$. The $\mathrm{GA}_{3}$ treated leaves after 10 days showed $\mathrm{NP}$ values lower than control leaves. The stomatal conductance $\left(\mathrm{gH}_{2} \mathrm{O}\right)$ was higher in TDZ treatments

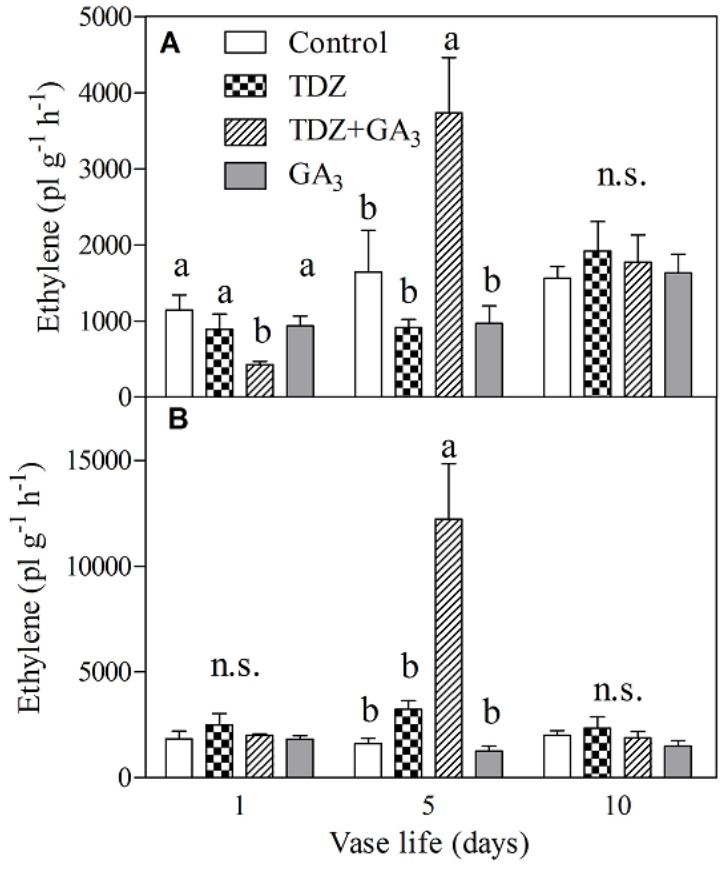

Figure 2. Ethylene production from flowers A) or leaves B) of cut stock harvested from cut stems pulse treated for $24 \mathrm{~h}$ with distilled water (Control), $5 \mu \mathrm{M}$ TDZ, $5 \mu \mathrm{M}$ plus $0.5 \mathrm{mM}$ $\mathrm{GA}_{3}$ or $0.5 \mathrm{mM} \mathrm{GA}_{3}$ under light conditions. Values are the means with the relative standard errors of six leaves randomly harvested. Data were subjected to one way analysis of variance and differences among treatments were analysed by Bonferroni post-test. Different letters denote significant differences at $\mathrm{P} \leq 0.05$.

than other treatments during the whole experimental period (Figure 3B). The $\mathrm{gH}_{2} \mathrm{O}$ values ranged from 122 to $28 \mathrm{mmol} \mathrm{m}^{-2} \mathrm{~s}^{-1}$ (Figure 3B) in control leaves at beginning of the experiment and $\mathrm{GA}_{3}$ treated leaves after 10 days of vase life respectively. The $\mathrm{gH}_{2} \mathrm{O}$ in control leaves decreased by $60 \%$ after 1 day of storage and continued to decline until it reached $41 \mathrm{mmol} \mathrm{m}^{-2} \mathrm{~s}^{-1}$ after 10 days. The ALVPD did not significantly change among treatments (Figure $3 \mathrm{C}$ ). The WUE values of TDZ and 


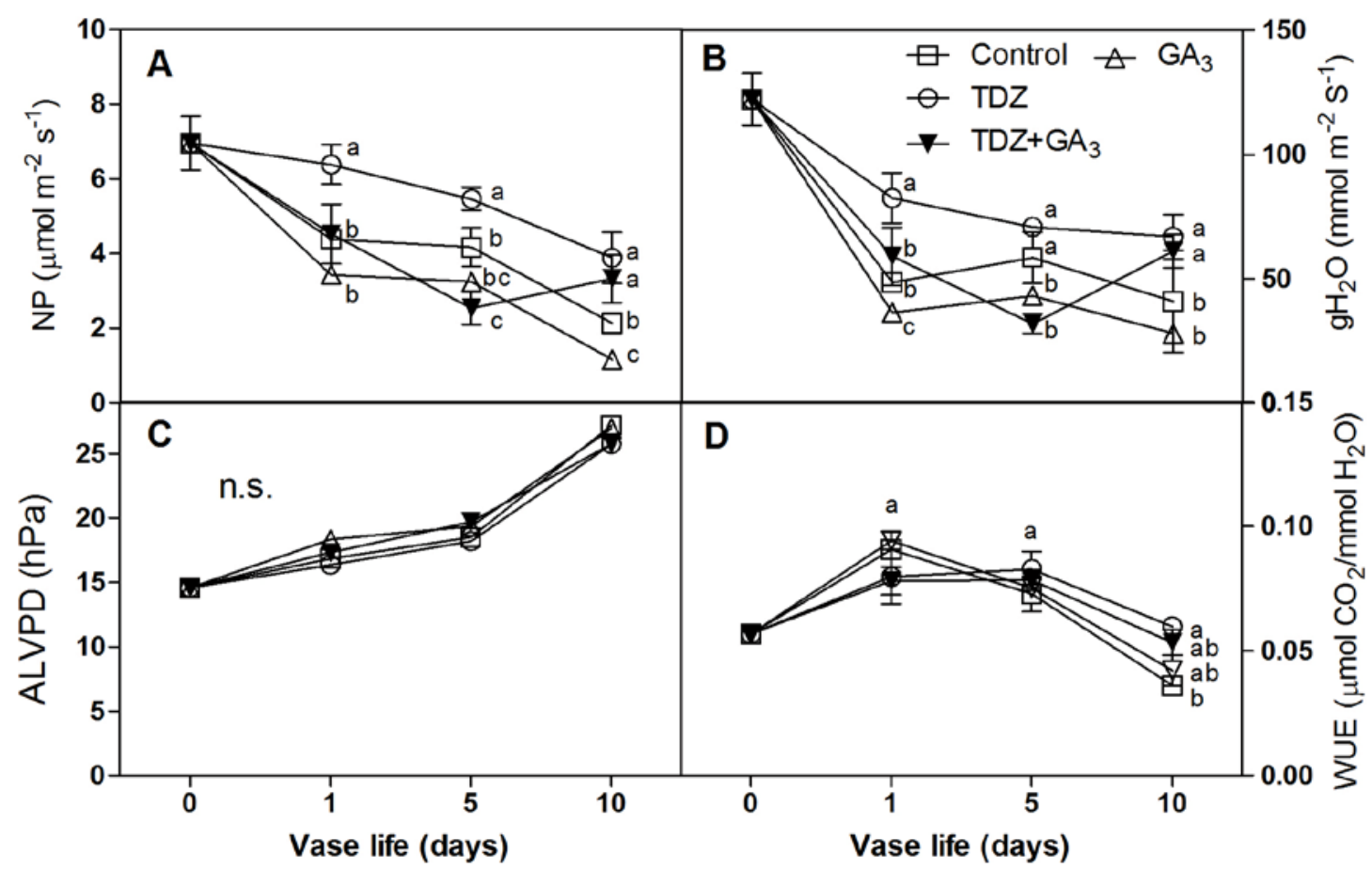

Figure 3. Leaf gas exchanges measured from leaves of cut stock flowers pulse treated for $24 \mathrm{~h}$ with distilled water (Control), $5 \mu \mathrm{M}$ TDZ, $5 \mu \mathrm{M}$ TDZ plus $0.5 \mathrm{mM} \mathrm{GA}_{3}, 0.5 \mathrm{mM} \mathrm{GA}_{3}$ under light conditions. A) Net photosynthesis (NP), B) Stomatal conductance $\left(\mathrm{gH}_{2} \mathrm{O}\right)$, C) Air to Leaf Vapour Pressure Deficit (ALVPD), D) Water Use Efficiency (WUE). Values are the means with the relative standard errors of six leaves randomly harvested. Data were subjected to one way analysis of variance and differences among treatments were analysed by Bonferroni post-test. Different letters denote significant differences $\mathrm{P} \leq 0.05$.

TDZ plus $\mathrm{GA}_{3}$ treated leaves increased after 1 day and remained constant until 5 days of storage then declined, but after 10 days were still higher than control and $\mathrm{GA}_{3}$ (Figure 3D).

\subsubsection{Chlorophyll a fluorescence}

The health status of leaves was monitored by chlorophyll a fluorescence that was measured using a portable fluorometer. The main fluorescence parameters Fo, $\mathrm{Fm}$ and $\mathrm{Fv} / \mathrm{Fm}$ were monitored during vase life in all treatments. The Fv/Fm ratio declined in leaves of control flowers. Cut flower stems treated with TDZ, TDZ plus $\mathrm{GA}_{3}$ or $\mathrm{GA}_{3}$ did not show a significant reduction of $\mathrm{Fv} / \mathrm{Fm}$ ratio (Figure $4 \mathrm{~A}$ ) during the experiment. The $\mathrm{Fv} / \mathrm{Fm}$ ratio ranged from 0.81 to 0.66 . The $\mathrm{Fm}$ values showed the same trend of $\mathrm{Fv} / \mathrm{Fm}$ without significant reduction in TDZ, TDZ plus $\mathrm{GA}_{3}$ or $\mathrm{GA}_{3}$ treatments (Figure 4B). The Fo values increased in all treatments stored at light conditions (Figure $4 \mathrm{C}$ ). The Fo values of control leaves sharply increased after 7 days of storage, while in all other treatments (TDZ, TDZ plus $\mathrm{GA}_{3}$ or $\mathrm{GA}_{3}$ ) the Fo values significantly increased after 10 days of storage.

\section{Discussion}

Stock flowers are very sensitive to leaf yellowing that occurs before the flower senescence, usually within 4-10 days after harvest [3,12]. The storage or transportation of cut flowers, cuttings or cut branches in dark may strongly induce chlorophyll breakdown, especially if the postharvest temperature is not carefully maintained below $5-6^{\circ} \mathrm{C}$ [13]. The period of time spent in dark may activate the physiological processes that lead leaves to yellowing. Treatments with TDZ were able to inhibit or delay chlorophyll degradation in cut stock flowers in light conditions. Analogous results have been obtained in studies of other cut flowers such as alstroemeria, tulips and chrysanthemum [2,14]. The physiological effect of TDZ is due to its cytokinin-like activity that is higher than benzyladenine. TDZ is not metabolized by the plants therefore its activity lasts longer than that of other cytokinins [8]. Moreover, it has been found that TDZ might promote the conversion of cytokinin ribonucleotides to more biologically active ribonucleosides [15]. These evidences might be the explanation of its effects on plants. Unfortunately, TDZ in dark conditions is less effective ininhibiting chlorophyll degradation. The reduced effect of TDZ might be due to 


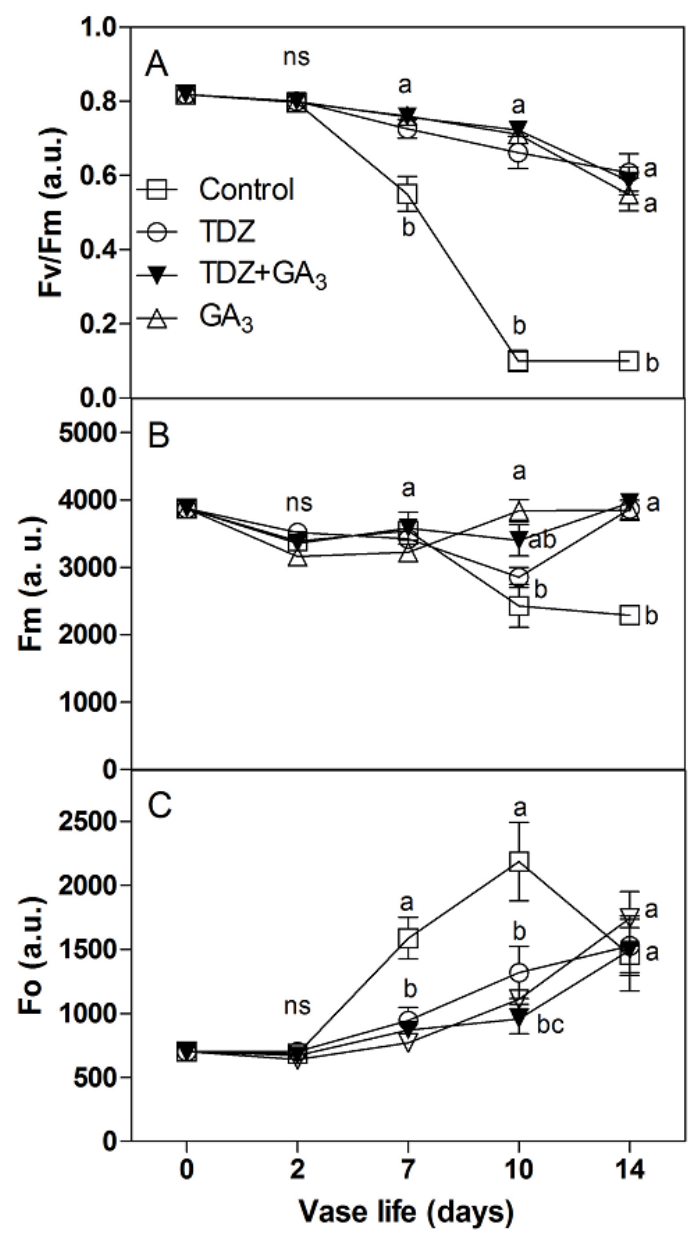

Figure 4. Chlorophyll a fluorescence measured from leaves of cut stock flowers pulse treated for $24 \mathrm{~h}$ with distilled water (Control), $5 \mu \mathrm{M}$ TDZ, $5 \mu \mathrm{M}$ plus $0.5 \mathrm{mM} \mathrm{GA}$ or $0.5 \mathrm{mM}$ $\mathrm{GA}_{3}$ under light conditions. A) Fo, B) $\left.\mathrm{Fm}, \mathrm{C}\right) \mathrm{Fv} / \mathrm{Fm}$. Values are the means with the relative standard errors of six leaves randomly harvested. Data were subjected to one-way analysis of variance and differences among treatments were analysed by Bonferroni post-test. Different letters denote significant differences at least $\mathrm{P}<0.05$.

its inactivation or by the lack of light in the chlorophyll turnover. In fact, in the biosynthesis of chlorophyll, the last step is mediated by NADH protochlorophyllide reductase, which converts the protochlorophillide to chlorophyllide, and this process requires light [16]. Some previous studies have suggested that light regulates chlorophyll biosynthesis at transcriptional level while the cytokinins act at the post-trascriptional level $[8,15,17]$. The relationship between cytokinins and chlorophyll metabolism has also studied in light and dark grown wheat plants. Results showed that dark-grown wheat plants had 10 fold lower amount of cytokinins compared to those grown in light conditions [18]. These results confirm that cytokinins content and chlorophyll degradation are directly correlated.
TDZ was used in combination with $\mathrm{GA}_{3}$ for investigating their combined effects in preventing leaf yellowing, especially under dark conditions. The idea of combination of $\mathrm{GA}_{3}$ with TDZ came from several investigations that demonstrated the effect of $\mathrm{GA}_{3}$ in delaying leaf yellowing in cut flowers. Applications of $\mathrm{GA}_{3}$ or $\mathrm{GA}_{4+7}$ alone or in combination with benzyladenine were able to reduce leaf yellowing in lilies and alstroemeria $[2,4,19]$. In our study $\mathrm{GA}_{3}$ did not show any synergic effect with TDZ and did not improve TDZ efficiency in dark conditions. In fact, $\mathrm{GA}_{3}$ alone did not satisfactory delay the leaf yellowing of stock flowers. These results suggest that TDZ and gibberellins have different targets and delay leaf senescence by working on different pathways.

Studies carried out on cotton and Pelargonium cuttings using TDZ showed an increase of ethylene production [20-22]. In our experiments ethylene production was stimulated only when TDZ was combined with $\mathrm{GA}_{3}$. The ability of TDZ and $\mathrm{GA}_{3}$ in combination to stimulate ethylene production may be used for practical applications such as promoting leaf abscission. The role of TDZ-induced ethylene in leaf abscission has been extensively shown using ethylene inhibitors such as silver thiosulphate (STS). Treatments with STS completely prevented leaf abscission [20], suggesting that the effect of TDZ has to be studied considering sensitivity of leaves or flowers. Therefore, the absence of ethylene negative effects may be explained by varying ethylene sensitivity in different species. This hypothesis might be confirmed by considering the relationship between endogenous cytokinins and ethylene sensitivity. Transgenic petunias that over-produce cytokinins showed that the higher level of cytokinins content was correlated with lower flower sensitivity to exogenous ethylene [23]. Moreover, the climacteric ethylene peak in these plants was delayed and flower life prolonged. Gene expression studies performed on Pelargonium cuttings did not identify the reason of ethylene increase and suggested that TDZ probably induces an unknown ACC synthase gene [24].

The leaf gas exchanges measured by exposure of stored stems to $400 \mu \mathrm{mol} \mathrm{m}^{-2} \mathrm{~s}^{-1}$ light intensity indicated that leaf functionality was preserved in TDZ treatments as demonstrated by NP values and related parameters measured. The high values of stomatal conductance and ALVPD indicate that gas exchange ispreserved by TDZ. These results were also observed in cut flowers treated with cytokinins that increase leaf transpiration and stomata opening [25]. The decline of NP values is associated to a reduction of maximum quantum efficiency of photosystem II (Fv/Fm) that is unavoidable during storage [26]. Chlorophyll a fluorescence is a non- 
invasive method for evaluating stress conditions in plants. In floriculture, it has been used for monitoring the quality of potted plants and cut flowers during transportation. Fluorescence parameters were also used for evaluating the efficiency of treatments in preserving Bougainvillea and roses $[27,28]$. However, the Fv/Fm and Fm values were higher in TDZ and $\mathrm{GA}_{3}$ treated flowers indicating the positive effects of these two plant growth regulators on leaf health.

In conclusion, our results demonstrate that in light conditions leaf yellowing can be best avoided by using pulse treatments with TDZ. The efficiency of treatments can be seen at $5 \mu \mathrm{M}$, while higher concentrations do not give any additional benefit. Combination of TDZ

\section{References}

[1] Buchanan-Wollaston V., Earl S., Harrison E., Mathas E., Navabpour S., Page T., et al., The molecular analysis of leaf senescence - a genomics approach, Plant Biotechnol. J., 2003, 1, 3-22

[2] Ferrante A., Hunter D.A., Wesley P.H., Reid M.S., Thidiazuron - a potent inhibitor of leaf senescence in Alstroemeria, Postharvest Biol. Techn., 2002, 25, 333-338

[3] Celikel F.G., Reid M.S., Postharvest handling of stock (Matthiola incana), HortSci., 2002, 37, 144-147

[4] Jordi W., Stoopen G.M., Kelepouris K., Van Der Krieken W.M., Gibberellin-induced delay of leaf senescence of Alstroemeria cut flowering stems is not caused by an increase in the endogenous cytokinin content, J. Plant Growth Regul., 1995, 14, 121-127

[5] Gan S.S., Amasino R.M., Cytokinins in plant senescence: from spray and pray to clone and play, Bioassays, 1996, 18, 557-565

[6] Philosoph-Hadas S., Michaeli R., Reuveni Y., Meir S., Benzyladenine pulsing retards leaf yellowing and improves quality of goldenrod (Solidago canadensis) cut flowers, Postharvest Biol. Technol., 1996, 9, 6573

[7] Van Doorn W.G., Hibma J., De-Wit J., Effect of exogenous hormones on leaf yellowing in cut flowering branches of Alstroemeria pelegrina L., Plant Growth Regul., 1992, 11, 445-448

[8] Genkov T., Ivanova I., Effect of cytokinin-active phenylurea derivatives on shoot multiplication, perioxidase and superoxide dismutase activities of in vitro cultured carnation, Bulg. J. Plant Physiol., 1995, $21,73-83$

[9] Lichtenthaler H.K., Chlorophylls and carotenoids: pigments of photosynthetic membranes, Methods Enzymol., 1987, 148, 350-382 with $\mathrm{GA}_{3}$ is not advisable because does not give any synergistic effect.

\section{Acknowledgements}

The present work was funded by MIPAAF "FLORPRO" Project 2007-2009 "Individuazione di tecniche di produzione, di conservazione e commercializzazione, finalizzate alla riduzione dell'impatto ambientale e all'ottimizzazione della qualità merceologica del prodotto".

[10] von Caemmerer S., Farquhar G.D., Some relationships between the biochemistry of photosynthesis and the gas-exchange of leaves, Planta, 1981,153, 376-387

[11] Francini A., Nali C., Picchi V., Lorenzini G., Metabolic changes in white clover clones exposed to ozone, Env. Exp. Bot., 2007, 60, 11-19

[12] Ferrante A., Vernieri P., Serra G., Tognoni F., Changes in abscisic acid during leaf yellowing of cut stock flowers, Plant Growth Regul., 2004, 43, 127-134

[13] Mutui T.M., Mibus H., Serek M., Effects of thidiazuron, ethylene, abscisic acid and dark storage on leaf yellowing and rooting of Pelargonium cuttings, J. Hort. Science Biotechnol., 2005, 80, 543-550

[14] Ferrante A., Mensuali-Sodi A., Serra G., Tognoni F., Treatment with thidiazuron for preventing leaf yellowing in cut tulips, and chrysanthemum, Acta Hortic., 2003, 624, 357-363

[15] Capelle S.C., Mok D.W.S., Kirchner S.C., Mok M.C., Effects of thidiazuron on cytokinin autonomy and the metabolism of $\mathrm{N}^{6}-\left(\Delta^{2}\right.$-isopentenyl $)\left[8-{ }^{14} \mathrm{C}\right]$ adenosine in callus tissues of Phaseolus lunatus $L$, Plant Physiol., 1983, 73, 796-802

[16] Kraepiel Y., Miginiac E., Photomorphogenesis and phytohormones, Plant Cell Env., 1997, 20, 807-812

[17] Flores S., Tobin E.M., Benzyladenine modulation of the expression of two genes for nuclear encoded chloroplast proteins in Lemna gibba: apparent posttranscriptional regulation, Planta, 1986, 168, 340349

[18] Banowetz G.M., Cultivars of hexaploid wheat of contrasting stature and chlorophyll retention differ in cytokinin content and responsiveness, Ann. Bot., 1997, 79, 185-190 
[19] Whitman C.M., Heins R.D., Moe R., Funnell K.A., $\mathrm{GA}(4+7)$ plus benzyladenine reduce foliar chlorosis of Lilium longiflorum, Sci Hortic., 2001, 89, 143-154

[20] Suttle J.C., Involvement of ethylene in the action of the cotton defoliant thidiazuron, Plant Physiol., 1985, 78, 272-276

[21] Yip W.K., Yang S.F., Effect of thidiazuron, a cytokininactive urea derivative, in cytokinin-dependent ethylene production systems, Plant Physiol., 1986, 80, 515-519

[22] Suttle J.C., Disruption of the polar auxin transport system in cotton seedlings following treatment with the defoliant thidiazuron, Plant Physiol., 1988, 86, 241-245

[23] Chang H., Jones M.L., Banowetz G.M., Clark D.G., Overproduction of cytokinins in petunia flowers transformed with PSAG12-IPT delays corolla senescence and decreases sensitivity to ethylene, Plant Physiol., 2003, 132, 2174-2183

[24] Mutui T.M., Mibus H., Serek M., Influence of thidiazuron, ethylene, abscisic acid and dark storage on the expression levels of ethylene receptors (ETR) and ACC synthase (ACS) genes in Pelargonium, Plant Growth Regul., 2007, 53, 87-96
[25] Wachowicz M., Skutnik E., Rabiza-Świder J., The effect of growth regulators on stomatal aperture in senescing cut leaves of Zantedeschia aethiopica Spr. and Hosta Tratt. 'Undulata Erromena', Folia Horticulturae, 2006, 18, 65-75

[26] Ferrante A., Maggiore T., Chlorophyll a fluorescence measurements to evaluate storage time and temperature of Valerianella leafy vegetables, Postharvest Biol. Technol., 2007, 45, 73-80

[27] Pompodakis N.E., Terry L.A., Joyce D.C., Lydakis D.E., Papadimitriou M.D., Effect of seasonal variation and storage temperature on leaf chlorophyll fluorescence and vase life of cut roses, Postharvest Biol. Technol., 2005, 36, 1-8

[28] Hossain A.B.M.S., Boyce A.N., Osman N., Postharvest quality, vase life and photosynthetic yield (chlorophyll fluorescence) of Bougainvillea flower by applying ethanol, Aust. J. Basic Appl. Sci., 2007, 1, 733-740 